\title{
Layer Transfer Approach to Opaline Hetero Photonic Crystals
}

\author{
Qingfeng Yan, Lay Kuan Teh, Qi Shao, C. C. Wong, Yet-Ming Chiang
}
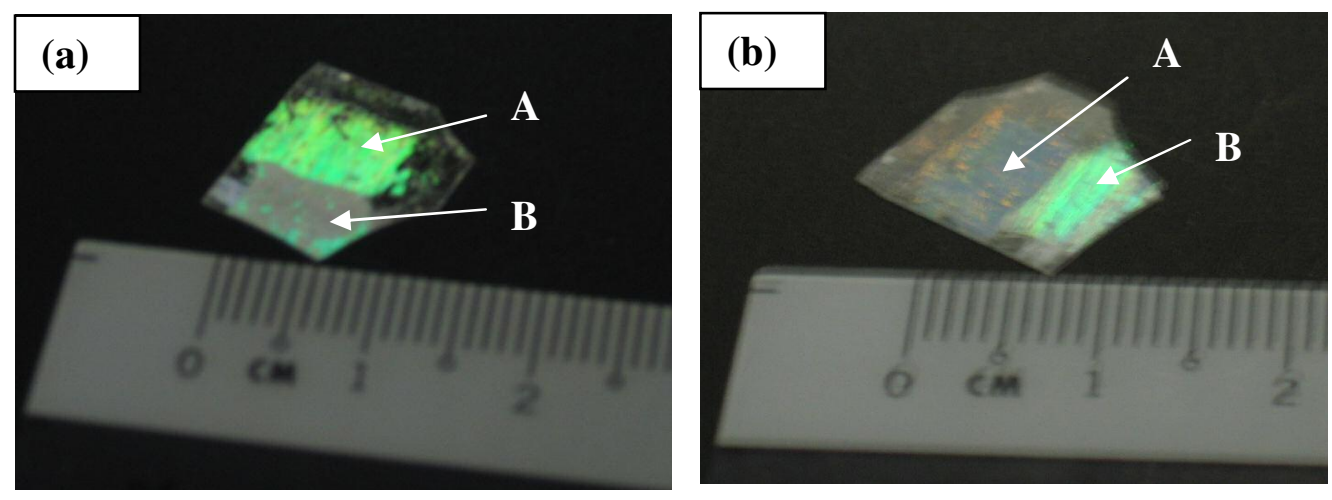

Figure S1. Photographs showing the colors reflected from a two-layer hetero colloidal crystal (PS 356nm on top and PS 482nm on bottom) from different viewing angles. Region A of the sample is the region where only the bottom layer PS $482 \mathrm{~nm}$ is present while region $\mathrm{B}$ is the two-layer structure. No detachment of the hetero colloidal crystal from the glass substrate happens. 


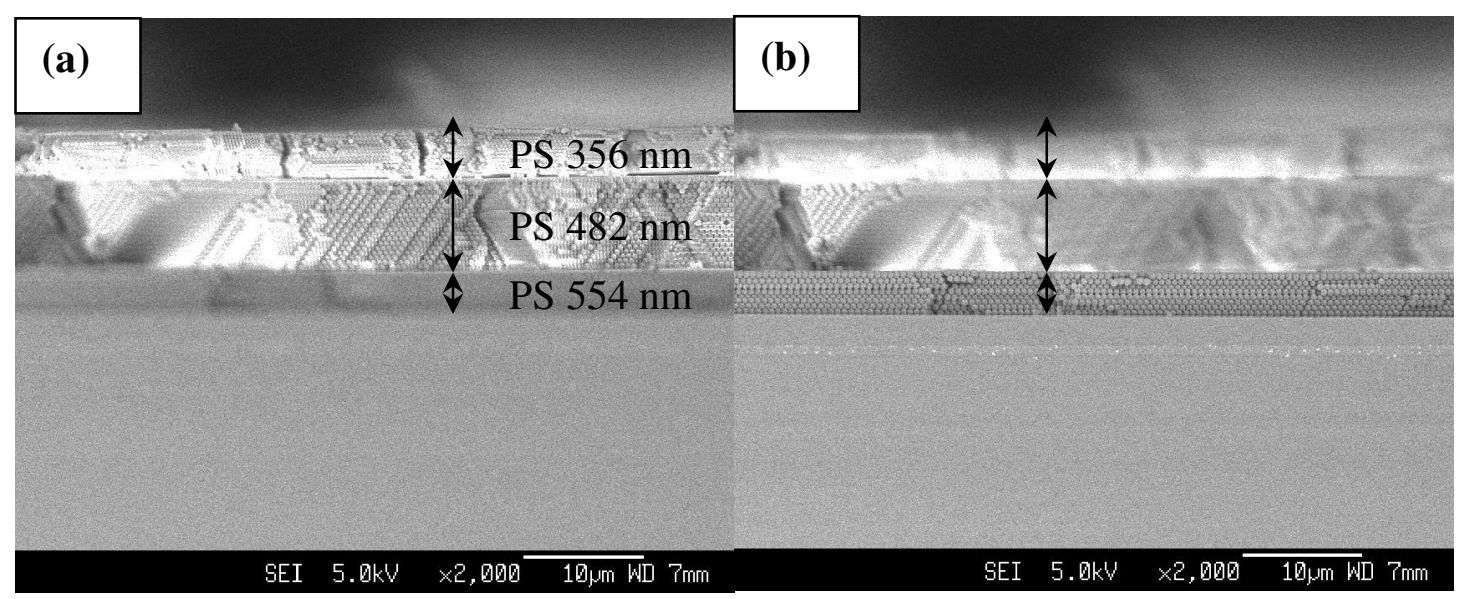

Figure S2. Cross-sectional view of a tri-layer opaline heterostructure (PS $356 \mathrm{~nm}$ opal at the top, PS $482 \mathrm{~nm}$ opal at the mid, and PS $554 \mathrm{~nm}$ opal at the bottom) prepared using a multiple transfer technique. Both (a) and (b) were imaged from the same position of the sample. The bottom PS $554 \mathrm{~nm}$ opal film looks blur in (a) due to difficulties in obtaining a cross-section with the edges of all three layers in the same plane. When the bottom PS $554 \mathrm{~nm}$ opal film is focused in (b), the top two layers become blur. 